\title{
Interfaces entre Psicologia e Direito: Desafios da Atuação na Defensoria Pública
}

Interfaces Between Psychology And Law: The Challenge Of Working At The Public Defender's

Office

Interfaces Entre Psicología Y Derecho: Desafíos De La Actuación En La Defensoría Pública

Marina Wanderley

Vilar de Carvalho

Defensoria Pública do

Estado de São Paulo
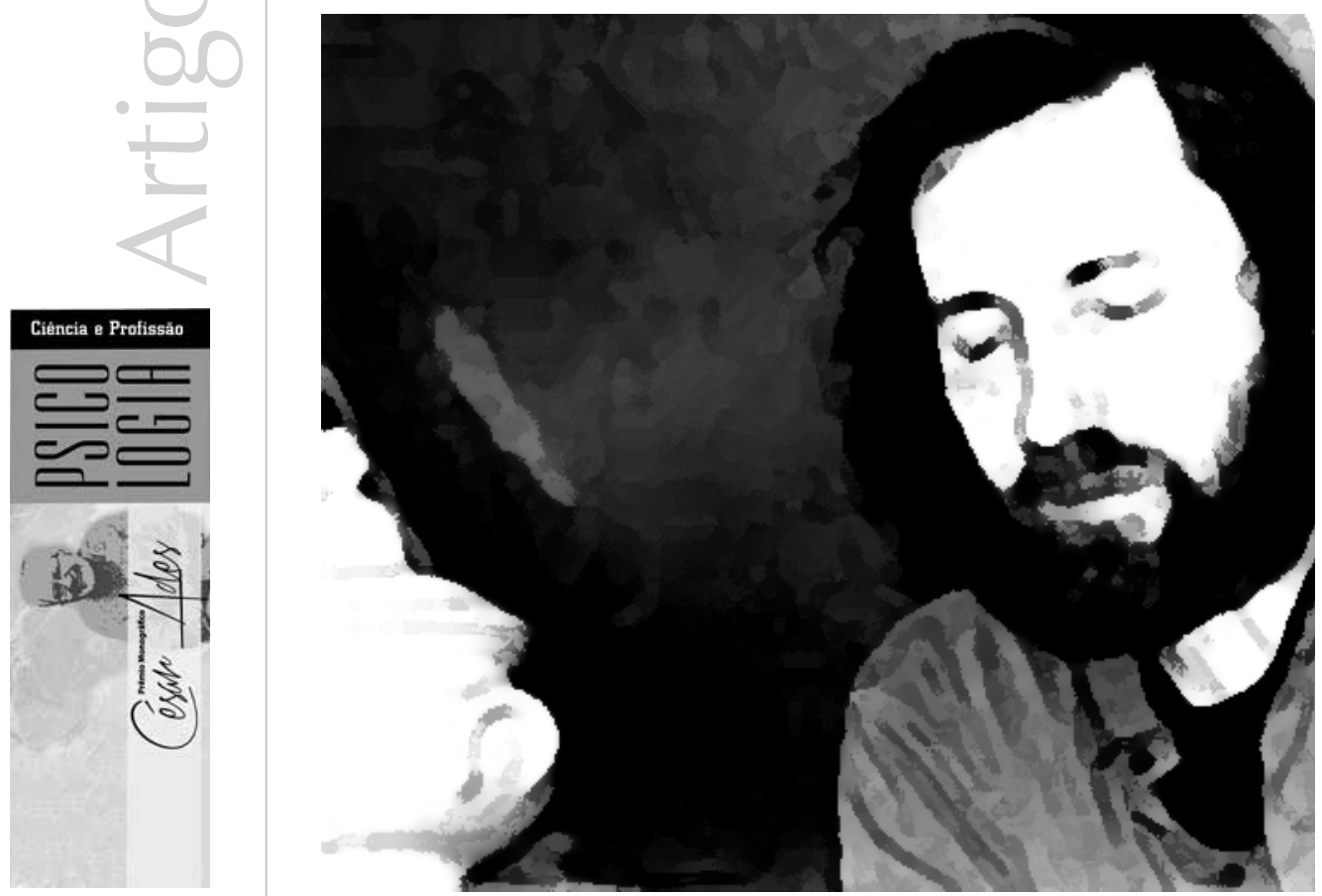
Atuar tendo

o devir como

subjetivação

é abrir a

possibilidade

para uma políica

de existência

que comporte

linhas de fuga

adutoras de outros

agenciamentos

possíveis (Perez,

Meza, Rossotti, \&

Bicalho, 2010, p.

196).

Resumo: O presente artigo propõe-se a narrar as experiências do início do trabalho da Psicologia na Defensoria Pública do Estado de São Paulo. Pretende-se, a partir de alguns casos encaminhados e de situações cotidianas no ambiente de trabalho, desenvolver reflexões críticas acerca das demandas endereçadas - tanto por parte dos usuários como dos outros profissionais -, de respostas possíveis e de colocar em análise o lugar que a Psicologia está sendo chamada a ocupar. Para tanto, uma ferramenta importante que se faz necessária é a análise de implicações, proposta pela análise institucional, em especial por René Lourau. Observa-se que as demandas se dividem em resoluções extrajudiciais de conflitos, apoio e encaminhamento para a rede de serviços municipais ou para acompanhamento psicológico. O desafio, na prática, é dirigir um olhar diferenciado a partir da compreensão das produções socio-histórico-econômico-familiares do sujeito de maneira a não reproduzir sofrimentos e opressões; é constantemente colocar-se como profissional envolvido na promoção da cidadania e na autonomia e no empoderamento dos sujeitos, é, em uma perspectiva ética, entender a nossa atuação como produtora de demandas, de verdades, de mundos. Palavras-chave: Psicologia forense. Análise institucional. Políticas públicas. Intervenção psicológica.

Abstract: This article aims at narrating the experiences regarding the outset of the psychology work at the São Paulo Public Defender's Office. Based on some practical cases, as well as daily situations in the work environment, critical reflections are developed concerning the demands addressed by users and other professionals, possible responses to these requests and an analysis of what place psychology is asked to occupy. In order to reach this goal, one important resource is the implication analysis proposed by the institutional analysis, especially by René Lourau. One observes that the demands are divided in extrajudicial conflicts resolutions, psychological support, indication to public services and to therapeutic accompaniment. Practically speaking, the challenge is to foster a different view which considers the comprehension of the social-historical-economic-familiar productions of the subject, so that one does not reproduce suffering and oppression; it is a matter of constantly placing oneself as a professional who is involved in promoting citizenship, autonomy and the empowerment of the subject; according to an ethic perspective, it means understanding our practice as a promoter of demands, truth and worlds. Keywords: Forensic psychology. Institutional analysis. Public policies. Psychological intervention.

Resumen: El presente artículo se propone narrar las experiencias del inicio del trabajo de la Psicología en la Defensoría Pública del Estado de São Paulo. Se busca, desde algunos casos encaminados y de situaciones cotidianas en el ambiente de trabajo, desarrollar reflexiones críticas acerca de las demandas direccionadas tanto por parte de los usuarios como de los demás profesionales -, de respuestas posibles y de poner en análisis el lugar que la Psicología está siendo llamada a ocupar. Para eso, una herramienta importante que se hace necesaria es el análisis de implicaciones, propuesta por el análisis institucional, en especial por René Lourau. Se observa que las demandas se dividen en resoluciones extrajudiciales de conflictos, apoyo y encaminamiento para la red de servicios municipales o para acompañamiento psicológico. El desafío, en la práctica, es dirigir una visión diferenciada a partir de la comprensión de las producciones socio-histórico-económico-familiares del sujeto de manera de no reproducir sufrimientos y opresiones; es constantemente situarse como profesional involucrado en la promoción de la ciudadanía y en la autonomía y en el empoderamiento de los sujetos, es, en una perspectiva ética, entender nuestra actuación como productora de demandas, de verdades, de mundos. Palabras clave: Psicología judicial. Análisis institucional. Políticas públicas. Intervención psicológica.

A Defensoria Pública consiste em um dos órgãos denominados pela Constituição Federal de 1988 como "funções essenciais à Justiça", ou seja, atua perante o Judiciário sem fazer parte da sua estrutura. $\mathrm{O}$ art. $5^{\circ}$, LXXIV da Constituição prevê a assistência jurídica integral e gratuita exercida aos que comprovarem insuficiência de recursos, através da Defensoria Pública.

A Lei Complementar no 988, de 9/01/2006, organiza a Defensoria Pública do Estado de São Paulo, e, de acordo com esta (Art. $3^{\circ}$ ), "a Defensoria Pública do Estado, no desempenho de suas funções, terá como fundamentos de atuação a prevenção dos conflitos e a construção de uma sociedade livre, justa e solidária, a erradicação da pobreza e da marginalidade, e a redução das desigualdades sociais e regionais".

A mesma lei prevê que existam profissionais de outras disciplinas para trabalhar em conjunto com o Direito no alcance dos objetivos da instituição, dentre eles os psicólogos: 
Artigo 48 - As Defensorias Públicas Regionais e a Defensoria Pública da Capital serão capacitadas com ao menos 1 (um) Centro de Atendimento Multidisciplinar, visando ao assessoramento técnico e interdisciplinar para o desempenho das atribuições da instituição (...)

Artigo 70 - Para o desempenho de suas atribuições, os Centros de Atendimento Multidisciplinar poderão contar com profissionais e estagiários das áreas de Psicologia, serviço social, Engenharia, Sociologia, Estatística, Economia, Ciências Contábeis e Direito, dentre outras. (Brasil, 1988)

Somente em abril de 2010 a primeira turma de psicólogos e assistentes sociais tomou posse e começou a implementar os Centros de Atendimento Multidisciplinar (CAM) em todas as regionais do Estado.

Desde o início, o discurso institucional versava sobre a ansiedade com a chegada desses profissionais de outras áreas, mas pouco se sabia o que ao certo nos caberia. Não se tinha notícia de outra Defensoria Pública estadual que já tivesse implantado esse quadro multiprofissional. Cada regional se abriu e se adaptou de maneira diferente; cada profissional acabou por imprimir sua forma de trabalho, diante do contexto de inauguração que se viveu.

O presente artigo propõe-se a narrar as vivências da autora, única psicóloga do CAM em uma cidade da região metropolitana de São Paulo, no primeiro ano de implementação desse centro. Fazer parte da construção de um serviço é um grande desafio, mais ainda por tratar-se de um novo lugar que a Psicologia ocupa em instituições jurídicas, campo que vem crescendo em larga escala nos últimos anos. Ser pioneiro na criação de um serviço pode encher de orgulho o profissional, mas também traz momentos de angústia, de grande responsabilidade.

O objetivo do presente texto é desenvolver reflexões críticas acerca das demandas endereçadas tanto por parte dos usuários como dos outros profissionais, obter respostas possíveis e colocar em análise o lugar que a Psicologia está sendo chamada a ocupar e o lugar em que tenho me colocado como profissional, produzindo um caminho de escolhas e de delimitações sobre o que tem significado a inserção da Psicologia nessa instituição eminentemente judiciária que é a Defensoria Pública.

Para construir esse trabalho, uma ferramenta importante que se faz necessária é a análise de implicações, proposta pela análise institucional, em especial por René Lourau. Como nos explicam Coimbra e Nascimento:

A proposta de analisar nossas implicações é uma forma de pensar, cotidianamente, como vêm se dando nossas diferentes intervenções. (...) Colocar em análise o lugar que ocupamos, nossas práticas de saber-poder enquanto produtoras de verdades - consideradas absolutas, universais e eternas - seus efeitos, o que elas põem em funcionamento, com o que se agenciam é romper a lógica racionalista presente no pensamento ocidental. (2007, p. 29)

Entendemos que qualquer intervenção é um posicionamento ético-político e, portanto, não neutro, sendo sempre preciso colocar em análise as produções dos nossos discursos, dos nossos posicionamentos como profissionais da Psicologia. Conforme Alvarenga Filho,

(...) acreditamos que as diferentes práticas e saberes da Psicologia podem servir tanto para legitimar e reforçar opressões e violências como também para construir novos mundos, novas maneiras de viver, de sonhar, de sentir, de amar. Cabe-nos o dever ético de sempre interrogarmos nossas práticas a fim de colocar em análise os efeitos que produzem. (2010, p. 118)

Pretendemos, portanto, promover ao longo do texto análises das implicações, fazendo uso também de trechos de diário de campo $^{1}$. Procuramos refletir sobre os casos encaminhados à Psicologia e sobre algumas situações cotidianas no ambiente de trabalho para problematizar a inserção da Psicologia 
2 Conforme nos explica Deleuze, Espinosa reverte a forma dicotômica, natural e moral de opor o Bem e o Mal para uma perspectiva do encontro, em que o bom e o mau são produzidos na relação e são diferenças qualitativas de modos de existência. A ética, assim,

substitui a moral, em um plano imanente (em oposição a valores transcendentes) e "considera em cada caso somente o poder de ser afetado" (2002, p. 33).

3 Esta é a nomenclatura atual para o estudo que é realizado pelos psicólogos no contexto de execução penal.

4 Com o intuito de não expor as pessoas envolvidas nos casos e nas situações a serem relatados, nenhum nome será divulgado, e as categorias defensores(as) e estagiários(as) serão sempre colocadas no masculino, no sentido generalista. na Defensoria Pública: as tentativas e os erros e os acertos cotidianos, em uma perspectiva espinosista do encontro, da potência, da ética ${ }^{2}$, entendendo a nossa atuação como produtora de demandas, de verdades, de mundos.

Historicamente, a relação entre Psicologia e Direito iniciou-se no final do século XIX com a Psicologia do testemunho, e, desde então, voltava-se prioritariamente para a prática de perícia, para o exame criminológico ${ }^{3}$, para a aplicação de testes e a realização de psicodiagnósticos. Todas essas práticas de observação, de classificação e de registro do comportamento visavam à avaliação e à classificação dos indivíduos a fim de legitimar as práticas e as decisões judiciais e a normalizar aqueles submetidos ao sistema (Foucault, 2005; Brito, 1999; Jacó-Vilela, 1999). Como se vê, a Psicologia jurídica nasceu bastante atrelada à área criminal, mas acabou por expandir-se para as áreas da infância e da família, entre outras.

Ao longo dos últimos anos, diversas práticas foram sendo construídas, partindo de novos paradigmas, de um olhar crítico sobre os efeitos das produções da Psicologia em parceria com o Direito. São ideias que trazem os princípios dos direitos humanos para o cerne do debate sobre a inserção da Psicologia em qualquer locus, que refletem sobre o profissional que está ligado à promoção da cidadania e ao empoderamento dos sujeitos, que os compreende em sua totalidade, ou seja, contextualizando-o social, histórica e culturalmente em uma perspectiva de inclusão social.

\section{A introdução da Psicologia na Defensoria} Pública também se insere neste debate, e acaba por constituir-se como um novo e importante analisador para se refletir acerca das práticas e dos saberes produzidos pela Psicologia nos dias atuais. Cabe, assim, questionar em que medida esse novo locus de atuação é mais um espaço que demanda práticas de herança positivista e/ou que endereça novas demandas à Psicologia.

A Defensoria Pública ocupa um lugar ímpar nas práticas judiciárias, pois não faz parte do Poder Judiciário, mas funciona como mola propulsora, pois é através dela que alguns cidadãos dão entrada em processos jurídicos - ou acessam os seus direitos. Nesse sentido, é interessante pensar nas funções da Psicologia nessa instituição: que lugar e que prática os psicólogos estão sendo convidados a ocupar, a realizar, que relações de poder estão aí envolvidas, que forças estão atravessadas na produção dessa demanda e quais as diferenças em relação aos profissionais que trabalham no Poder Judiciário propriamente dito, se é que existem.

\section{O cotidiano na Defensoria Pública}

Imaginemos a seguinte situação genérica, protagonizada por uma pessoa de baixa renda, moradora da região metropolitana de São Paulo: uma pessoa procura a Defensoria Pública em busca do alcance de seus direitos - aquilo que ela sabe, de alguma forma, que pode alcançar através da Justiça. Esta é personificada na figura do Juiz, aquele que tem poderes para descobrir a verdade e para decidir sobre a vida das pessoas. Sua decisão é neutra, sábia e, portanto, inquestionável. Para ter acesso à Justiça, é preciso ter advogado; aos poucos, as pessoas descobrem que podem ter acesso ao advogado gratuito, o Defensor Público. Este será, assim, aquele que as ajudará a chegar ao Juiz e a provar que elas falam a verdade, que estão passando por um conflito grave, que necessitam da solução daquele conflito de uma certa maneira, e urgente. Eis que, ao contar seu caso ao defensor ${ }^{4}$, este o encaminha para "conversar com a psicóloga".

Cabe destacar que, dentre os princípios do CAM previstos na Deliberação n ${ }^{\circ}$ 187, de 12 de agosto de 2010, do Conselho Superior da 
5 Na Defensoria Pública, as pessoas que procuram seus serviços são chamadas de assistidos, em referência à assistência jurídica prestada pela

instituição. Mas esse nome também pode ser associado ao assistencialismo, prática que se aproxima da caridade e que coloca aquela pessoa no lugar de dependente e que não caminha no sentido de potencializar sua autonomia, mas sim,

de perpetuar seu lugar de coitado. Por isso, os psicólogos e os assistentes sociais optaram por chamar

essas pessoas de usuários (de um serviço), nome mais comum nas práticas psicossociais.

6 Trata-se da Monografia "A Psicologia na

Defensoria Pública:

a busca pela justiça e os novos desafios "psis"", apresentada ao Curso do

Especialização em Psicologia Jurídica da Universidade

Estadual do Rio de Janeiro, em 2011, sob orientação da

Professora Doutora Anna Paula Uziel.
Defensoria Pública do Estado, temos (Art. 1ํ):

XII - Não obrigatoriedade da submissão do usuário ao atendimento psicossocial como condição à assistência jurídica;

XIV - Informação ao usuário em relação à existência, ao propósito e à natureza do atendimento psicossocial.

Em outras palavras, o trabalho psicossocial deve ser sugerido, sem obrigação ou coação, mas ainda há muito a se modificar nessa cultura do encaminhamento. Para exemplificar, cito a atitude de um defensor que me chamou antes de consultar a usuária ${ }^{5}$ e disse, na frente dela: - Quero que você chame o ex-marido dela amanhã e faça um acordo para ele deixar a casa em 24h! Podemos discutir o sentido de um acordo que já se inicia com a solução pronta, vinda de outro que não as partes nem o juiz, que teria essa função. Também podemos refletir sobre a expectativa que essa usuária criou, tendo a certeza de que amanhã o marido dela sairia de casa. Nesse momento, utilizemos esse exemplo para refletir sobre as formas de encaminhamento ao CAM.

Alguns questionam o porquê da presença da psicóloga: - Eu acho que os advogados fizeram pouco caso e não mandaram uma intimação para eles, afirma a mãe que quer dar um basta no filho usuário de droga sem ter que chamar a polícia. Outros acham bom que haja esse serviço ali: - Esse serviço é novo, né? É bom saber que existe; - Ele precisa mesmo conversar com a psicóloga para abrir a mente dele, afirma a mulher que quer que o pai de seu filho pague a pensão corretamente sem correr o risco de ele ser preso.

A partir dos primeiros meses de trabalho, podemos dividir os casos que chegam à Psicologia em dois grandes grupos: demanda de tentativa de resolução de conflitos (familiares, em geral) e demanda de uma escuta diferenciada, de apoio e de encaminhamento para os locais corretos da cidade ou para acompanhamento psicológico. É fundamental destacar que essa diferenciação foi por mim construída e faz parte das análises constantes na monografia de conclusão de curso que deu origem ao presente texto ${ }^{6}$. Neste, nós nos debruçaremos sobre o segundo ponto: a escuta psi.

\section{A escuta psi}

Neste tipo de demanda, é um pouco mais clara a função de um profissional da Psicologia, pois aproxima-se da concepção de senso comum acerca dessa disciplina. Como podemos observar nas observações acima e também, por exemplo, na demanda da mãe que precisa de ajuda para lidar com a filha que sofreu violência sexual, o senso comum parece apresentar uma ideia da Psicologia como aquela que realiza uma análise sobre o pensamento e a vida de uma pessoa, que tem respostas sobre como vivenciar um sofrimento, ou ainda que vai convencer alguém sobre a forma correta de ser. De acordo com Coimbra, Ayres e Nascimento,

O psicólogo aparece, então, como alguém com condições para ajudar os outros na busca daquilo que é denominado felicidade, equilíbrio ou algo parecido, sendo ele capaz de acompanhar os destinos das pessoas, converter, muitas vezes, suas percepções e 'consciências'; estruturar e transformar personalidades. Enfim, supostamente 'humanizar'. (2008a, p. 28)

A escuta clínica realiza um trabalho a partir do discurso de uma pessoa, de como esta narra e vivencia os acontecimentos de sua vida, seus conflitos e sofrimentos, ou seja, de sua realidade simbólica. Longe de desqualificar esse espaço de atuação profissional, pois entendemos que ele é bastante importante para uma pessoa que está em sofrimento ou que busca novas formas de lidar com os acontecimentos e relacionamentos de sua vida, a questão que fica é a expectativa endereçada a esse profissional e, no caso, se a um psicólogo inserido na Defensoria Pública cabe trabalhar sob esse formato. 
"o cotidiano

é esvaziado politicamente; as relações de opressão, as explorações, as diversas formas de dominação são invisibilizadas e atribuídas ao território do psicológico, fazendo parte do psiquismo e da vida interior do sujeito" (Coimbra \& Leitão, 2009, p.

151).
Há uma demanda direcionada - pelo que se apresenta no cotidiano, naquelas pessoas que chegam ali somado à concepção que se tem da Psicologia (tanto por parte dos defensores como dos usuários). Como responder, então, a essa demanda? Um acolhimento, uma escuta, uma conversa reflexiva e, quem sabe, uma sugestão para um atendimento continuado. Essa postura não deixa de ser uma escuta clínica, visto que se propõe a escutar aquele sujeito em seu sofrimento, a partir do seu discurso de simbolização e da relação que se estabelece. É uma postura que aposta nas potências e nas multiplicidades dos indivíduos; é, ainda, uma postura que entende que esse posicionamento do psicólogo pode dar-se em qualquer lugar em que esse profissional é chamado a atuar. Como qualquer atitude, produz efeitos. Segundo Carvalho, Ayres e Farias,

A entrevista, assim, se faz como dispositivo de intervenção clínico-política, já que incide não apenas sobre a vida daquele que se apresenta mas também sobre a dos que com ele convivem e, não com menos importância, sobre a prática do psicólogo nesse espaço. (2008, pp. 83/84)

Há de se tomar cuidado para não se transformar em uma resposta de adequação ao modoindivíduo. Esse conceito é trabalhado por Regina Barros e coloca em análise a produção capitalística de um modo de ser indivíduo baseada em uma lógica individualizante, na existência de uma essencialidade do indivíduo e na meritocracia: "a totalização, a unidade, a generalização, a intimização e a identidade são características dominantes desse modo" (1994, p. 9). Parece-nos que as demandas para a Justiça, assim como para a Psicologia, seja por parte do usuário, seja do defensor público, fazem parte dessa lógica, pois buscam uma adequação dos indivíduos a um modelo padrão, correto, de existência. É para um enquadre no modo-de-ser-indivíduo que muitas vezes se procura a intervenção de outrem. A Psicologia, em especial, é chamada a dizer sobre a essência daquele indivíduo e, a partir desse conhecimento, adequá-lo a um certo padrão social.

Nesse ínterim, há de se tomar também o cuidado para não entrar em uma postura de psicologização do cotidiano, em que as questões sociais são reduzidas a um plano psíquico, quando "o cotidiano é esvaziado politicamente; as relações de opressão, as explorações, as diversas formas de dominação são invisibilizadas e atribuídas ao território do psicológico, fazendo parte do psiquismo e da vida interior do sujeito" (Coimbra \& Leitão, 2009, p. 151).

Entende-se a subjetividade como uma construção socio-histórica, que se dá na relação com o outro e com o mundo, que é atravessada por instâncias individuais, coletivas e institucionais. "O que nos interessa são modos de subjetivação e, nesse sentido, importa-nos poder traçar as circunstâncias em que eles se compuseram, que forças se atravessam e que efeitos estão se dando" (Passos \& Barros, 2000, pp. 77/78)

O recebimento dessa demanda, o acolhimento e o encaminhamento para um acompanhamento especializado é um caminho possível. A ressalva é para que esse caminho não se torne mecânico, generalizado e até mesmo uma forma de engessar aquele indivíduo ou de solucionar todos os problemas, imediatamente.

Cabe aqui uma questão importante: qual é a solução? Quem é que dá a solução e para quem? O encaminhamento de um defensor à Psicologia pode significar uma forma de passar adiante um problema que ele não consegue resolver. Isso pode ser compreendido de diferentes maneiras: o seu saber não consegue abarcar todas as demandas e ele entende que outro saber pode viabilizar alguma resposta, ou ele quer livrar-se de um problema que não é dele, mas que passa a ser na medida em que ele se responsabiliza pelo caso, assume o trabalho, mas não consegue dar vazão a ele, 
recorrendo, então, a outra área, qualquer que seja ela, isto é, o encaminhamento pode ser uma forma de solucionar o seu problema. Não cabe aqui um juízo de valor acerca desses formatos, mas sim, a compreensão de que o encaminhamento pode ter múltiplos sentidos (para todas as partes envolvidas) e pode gerar muitos efeitos diferentes.

Por seu turno, será a Psicologia a responsável por dar uma solução? Que solução se espera ao se repassar a responsabilidade para essa disciplina? Refletindo a partir de uma perspectiva crítica com relação aos posicionamentos históricos da Psicologia, devemos pensar que esta tem a função não de conduzir o indivíduo a um caminho, de mostrar-lhe a verdade, de adequá-lo ao modo-de-ser-indivíduo, nem de reproduzir um lugar historicamente construído de necessitado, de quem precisa de assistência, mas de empoderá-lo. Coimbra, Ayres e Nascimento afirmam que

Talvez esse possa ser um desafio para a Psicologia no Judiciário: encontrar formas de atuação baseadas em um paradigma ético-político que afirme subjetividades críticas de sua realidade, com algum grau de autonomia perante suas vidas, condição que historicamente lhes vem sendo retirada. (2008b, p. 44)

Essa forma de atuação, contudo, não é tão simples de ser construída. Estamos atravessados por muitas forças. Há uma expectativa de que a disciplina nova possa alcançar soluções para casos com os quais até agora não se sabia o que fazer; há também uma demanda por diminuir a carga de trabalho na área do Direito; há ainda a expectativa de que essas respostas não sejam demoradas, e, por fim, há a demanda do usuário, que chegou à Defensoria Pública pedindo solução e, muitas vezes, para ele não importa quem será o responsável. $\mathrm{O}$ que fazer, então, diante de tantas demandas e expectativas?
A responsabilidade que temos em nossas mãos é poder de agir ou acaba transformando-se em ação de violência? Que soluções são dadas aos casos? Passar adiante, ou seja, transferir para outro profissional ou outro órgão é solucionar ou simplesmente se livrar do problema? E será que temos a obrigação de resolver tudo? É viável, é nossa função? E mais: sou eu quem resolve? A minha função não seria fazer com que as pessoas resolvam, ao menos nos casos de demanda de conciliação? (trecho do diário de campo)

Cabe, assim, colocar essa demanda em análise. Podemos entender que uma pessoa que está passando por um processo judicial - ou extrajudicial - pode estar em sofrimento por causa de todas as querelas que aquele processo tem posto à tona ou tem produzido. Como nos lembra Miranda Junior, "a instituição judiciária é sempre um lugar de trabalho com o sofrimento" (1998, p. 30), e a Defensoria Pública não parece distanciar-se disso. Quando uma das filhas procura ajuda para que todas as suas irmãs a auxiliem nos cuidados com a mãe, não só questões rotineiras e financeiras são ali discutidas, mas conflitos de toda uma vida, sentimentos de mágoa, de abandono, de preterimento com relação à mãe, além das diferenças e disputas entre as irmãs. Há, por vezes, também a vergonha por ter sido chamado um terceiro para resolver aquele conflito intrafamiliar. São sentimentos que se potencializam quando da disputa, da busca por definições, pela resolução daquele processo.

O que cabe à Psicologia? Parece-nos que, primeiramente, um respeito por todos esses sentimentos que atravessam os diálogos e as histórias; ao mesmo tempo, um cuidado para não ser o produtor desses sofrimentos, que passa por uma escolha do que é possível ser colocado em análise naquele processo e do que não cabe ressaltar, ao menos naquele momento, naquele contexto. Se uma das irmãs não se considera filha porque não fora criada por essa mãe e seu sentimento é, então, de abandono e mágoa, cabe à Psicologia 
chamar essa mulher a comprometer-se com os cuidados da mãe? Pela lei, todos os filhos têm obrigação com os pais idosos, e a definição de filho é pelo nome no registro de nascimento. Mas a Psicologia pode posicionar-se de uma forma não legalista (na letra da lei), o que não significa ilegal. Estar atento a todas as forças e sentimentos que atravessam as histórias que são ali contadas, os sofrimentos que são ali produzidos ou colocados à tona parece ser o diferencial dessa postura. Coimbra et al. observam que

É importante que possamos nos colocar como problematizadores das articulações coletivas que contemplem as diferentes instituições que atravessam o tecido social, o Judiciário e a nós próprios, ou seja, que possamos entender a Psicologia como uma prática política, uma ferramenta de intervenção social e nós, como sujeitos sempre comprometidos. (2008a, p. 37)

É fundamental nos entendermos como sujeitos implicados, queiramos ou não, na relação com a instituição, com as pessoas que dela fazem parte e com as pessoas que atendemos. No atendimento, na produção de conhecimento que se demanda a partir dele, somos afetados por essas pessoas, por esses encontros. Bons encontros são potência de ação, como nos ensina Espinosa (Deleuze, 2002). Não cabe imaginarmos que poderíamos ser pessoas neutras:

(...) o conhecimento é sempre uma certa relação estratégica em que o homem se encontra situado. É essa relação estratégica que vai definir o efeito de conhecimento, e por isso seria totalmente contraditório imaginar um conhecimento que não fosse em sua natureza obrigatoriamente parcial, oblíquo, perspectivo. (Foucault, 2005, p. 25)

O que cabe é a constante análise das implicações, ou seja, nós nos propormos a sempre refletir sobre os lugares que ocupamos, sobre os nossos posicionamentos e sobre o que produzimos a partir deles (Lourau, 2004; Coimbra \& Nascimento, 2008). Colocar-se como uma pessoa que se afeta e, ao mesmo tempo, que está comprometida com aquele sujeito é uma postura ética. Fuganti observa que

Chamamos ética (...) uma capacidade da vida e do pensamento que nos atravessa em selecionar, nos encontros que produzimos, algo que nos faça ultrapassar as próprias condições da experiência condicionada pelo social ou pelo poder, na direção de uma experiência liberadora, como num aprendizado contínuo". (2001, s.p.)

O desafio, na prática, é dirigir um olhar diferenciado a partir da compreensão das produções socio-histórico-econômicofamiliares do sujeito de maneira a não reproduzir sofrimentos e opressões, "é estranhar e recusar as essências, as naturalidades normalmente vinculadas ao eterno, à ahistoricidade. É, portanto, afirmar o diverso" (Coimbra \& Nascimento, 2008, p. 147). Importa conseguir ajudar essa família, por exemplo, a chegar a um consenso e a ter o entendimento de que ali não há espaço para trabalhar individual e terapeuticamente todas as questões, sugerindo, portanto, encaminhamentos para outros espaços, se for o caso.

Diante da percepção dessas demandas e do entendimento de que o acompanhamento psicológico não pode ser feito na Defensoria Pública por aquela profissional, foram estabelecidas, seis meses após o início do trabalho, parcerias com faculdades de Psicologia na região para que recebam gratuitamente em sua clínica-escola os usuários encaminhados através do CAM. Essa parceria foi muito bem aceita pelos defensores e também pelos que, até agora, receberam a sugestão.

Já recebi muitos agradecimentos pela escuta e pelos encaminhamentos, o que tem se configurado como um momento de grande satisfação profissional, de sensação de que há um motivo de estar ali, há um espaço a ser ocupado, há uma demanda por uma escuta diferenciada, que há sentido pensarmos na inserção da Psicologia na área jurídica. (trecho do diário de campo) 
Portanto, partindo da premissa de que o usuário pode escolher falar com a psicóloga, parece haver, em geral, um entendimento acerca da função dessa profissional e maior aceitação de seu trabalho, tanto por parte dos usuários como dos estagiários e dos defensores.

Todo esse caminho parece ter sido uma resposta para o que ouvi em um dos primeiros encontros com um defensor, quando ele afirmou: - Não pense que você vai fazer Psicologia aqui: ultrapassar as referências tradicionais e naturalizadas das possibilidades de atuação do profissional da Psicologia, alcançando uma postura crítica, conquistando espaço para constantemente reinventar nossas práticas, sem perder de vista nosso posicionamento ético-político e todas as forças que atravessam o lugar que ocupamos e que também que nos atravessam. 


\section{Marina Wanderley Vilar de Carvalho}

Mestre em Estudos da Subjetividade pela Universidade Federal Fluminense, Rio de Janeiro - RJ - Brasil.

E-mail: mawvilar@yahoo.com.br

Endereço para envio de correspondência:

Rua Boa Vista, 103, 10o andar, Centro. CEP: 01014-001. São Paulo, SP.

\section{Referências}

Alvarenga Filho, J. R. (2010). Seguindo estrelas e alimentando utopias: o desabrochar das muitas pétalas. In Formação: ética, política e subjetividades na psicologia (pp. 116-135). Rio de Janeiro: Conselho Regional de Psicologia.

Barros, R. D. B. (1994). Grupo: a afirmação de um simulacro. (Tese de Doutorado), Pontifícia Universidade Católica de São Paulo, SP.

Brasil. (1988). Constituição da República Federativa do Brasil. Recuperado em 23 janeiro, 2010, da http://www.planalto. gov.br

Brito, L. M. T. (1999). Rumos e rumores da psicologia jurídica. In A. M. Jacó-Vilela \& D. Mancebo (Orgs.),. Psicologia social - abordagens sócio-históricas e desafios contemporâneos (pp. 221-233). Rio de Janeiro: EdUERJ.

Carvalho, H. F., Ayres, L. S. M., \& Farias, M. C. (2008). A entrevista psicológica no Judiciário: um empreendimento político. In C. M. B. Coimbra, L. S. M. Ayres \& M. L. Nascimento (Orgs.). PIVETES - encontros entre a psicologia e o Judiciário (pp. 7784). Curitiba, PR: Juruá.

Coimbra, C. M. B., \& Nascimento, M. L. (2007). Sobreimplicação: práticas de esvaziamento político? In E. M. M. Arantes, M. L. Nascimento \& T. M. G. Fonseca (Orgs.), Práticas psi inventando a vida (pp. 27-38). Niterói, RJ: EdUFF.

Coimbra, C. M. B., \& Nascimento, M. L. (2008). Análise de implicações: desafiando nossas práticas de saber/poder. In A. R. R. Geisler, A. L. Abrahão \& C. M. B. Coimbra (Orgs.). Subjetividades, violência e direitos humanos: produzindo novos dispositivos em saúde (pp. 143-153). Niterói, RJ: EdUFF.

Coimbra, C. M. B., Ayres, L. S. M., \& Nascimento, M. L. (2008a). Construindo uma psicologia no Judiciário. In C. M. B. Coimbra, L. S. M. Ayres \& M. L. Nascimento (Orgs.). PIVETES - encontros entre a psicologia e o Judiciário (pp. 2538). Curitiba, PR: Juruá.

Coimbra, C. M. B., Ayres, L. S. M., \& Nascimento, M. L. (2008b). Cartografias jurídicas: discursos e práticas psi no Judiciário. In C. M. B. Coimbra, L. S. M. Ayres \& M. L. Nascimento (Orgs.). PIVETES - encontros entre a psicologia e o Judiciário (pp. 3947). Curitiba, PR: Juruá.

Coimbra, C. M. B., \& Leitão, M. B. S. (2009). Das essências às multiplicidades: especialismo psi e produções de subjetividades. In J. C. Mourão (Orgs.). Clínica e política 2 - subjetividade, direitos humanos e invenção de práticas clínicas (pp. 147-156). Rio de Janeiro: Abaquar/Grupo Tortura Nunca Mais.
Defensoria Pública do Estado de São Paulo. Deliberação CSDP $n^{\circ} 187$, de 12 de agosto de 2010. Disciplina a estrutura e o funcionamento dos Centros de Atendimento Multidisciplinar. Recuperado em 20 agosto, 2010, da http:// www.imprensaoficial.com.br

Deleuze, G. (2002). Sobre a diferença da ética em relação a uma moral. In G. Deleuze. Espinosa: filosofia prática (pp. 23-35). São Paulo: Escuta.

Foucault, M. (2005). A verdade e as formas jurídicas (3a ed.). Rio de Janeiro: NAU Ed.

Fuganti, L. (2001). A ética como potência e a moral como servidão. (Texto extraído de gravação de palestra realizada na Role Playing Pesquisa e Aplicação - SP). Recuperado em 24 junho, 2009, da http://www.roleplaying.com.br/content/seminarios/ eticapotencia.html

Jacó-Vilela, A. M. (1999). Os primórdios da psicologia jurídica. In L. M. T. Brito (Org.), Temas de psicologia jurídica (pp. 11-18). Rio de Janeiro: Relume Dumará.

Lourau, R. (2004). Implicação e sobreimplicação. In S. Altoé (Org.), René Lourau - analista institucional em tempo integral (pp. 186-198). São Paulo: Hucitec.

Lourau, R. (1995). Quarto encontro. In R. Lourau. Análise institucional e práticas de pesquisa (pp. 77-92). Rio de Janeiro: NAPE/UERJ. Recuperado em 06 setembro, 2008, da www. cliopsyche.cjb.net

Miranda Júnior, H. C. (1998). Psicologia e justiça. A psicologia e as práticas judiciárias na construção do ideal de justiça. Psicologia: Ciência e Profissão, 18(1), 28-37. doi: http://dx.doi. org/10.1590/S1414-98931998000100004

Passos, E., \& Barros, R. A. (2000). Construção do plano da clínica e o conceito de transdisciplinaridade. Psicologia: Teoria e Pesquisa, 16(1), 71-79. doi: http://dx.doi.org/10.1590/S010237722000000100010

Perez, A. C., Meza, A. P., Rossotti, B. G. P. P., \& Bicalho, P. P. G (2010). Da ética e da formação: cartografando práticas para além das normas. In Formação: ética, política e subjetividades na psicologia (pp. 178-198). Rio de Janeiro: Conselho Regional de Psicologia.

São Paulo. Assembleia Legislativa do Estado de São Paulo. Lei Complementar $n^{\circ}$ 988, de 9 de janeiro de 2006. Organiza a Defensoria Pública do Estado, institui o regime jurídico da carreira de Defensor Público do Estado. Recuperado em 21 janeiro, 2010, da http://www.al.sp.gov.br 